\title{
El manga de ciencia ficción: la distopía como reflejo de las inquietudes de la sociedad japonesa
}

\author{
Science-Fiction manga: Dystopia as a \\ reflect of the Japanese society concerns \\ Juan Luis Lorenzo Otero
}

Universidade de Santiago de Compostela

Juan Luis Lorenzo Otero. Licenciado en Historia del Arte por la Universidad de Santiago de Compostela. Máster en Gestión del Patrimonio, Museos y Mercado del Arte por la Universidad de Santiago de Compostela y la Universidad de Las Palmas de Gran Canaria. Comisario de la exposición Autómatas del Consumo en la Galería El Taller (Santiago de Compostela). Actualmente realizando su tesis doctoral dentro del grupo de investigación HAAYDU del departamento de Historia del Arte de la facultad de Geografía e Historia de la USC y cuyo título será: Rockstar Games. Innovación, investigación e intermediación en el arte del videojuego.

Fecha de recepción: 6 de noviembre de 2017

Fecha de aceptación definitiva: 21 de mayo de 2018 


\title{
Resumen
}

En la sociedad actual, el manga se ha convertido en una importante industria cultural japonesa que se ha exportado a todo el globo. A causa de esto, sus principales valores sociales han migrado a un grupo de consumidores a los que, originalmente, no estaba destinado. Dentro de este traspaso de información, destaca la presencia de una serie de títulos, inscritos en la ciencia ficción, cuya narración presenta un mundo de carácter distópico y apocalíptico. Este artículo busca indagar en la significación y temas presentes en aquellos mangas que se adentran en una temática de ciencia ficción distópico.

Palabras clave: manga, distopía, ciencia ficción, narrativa, estética.

\begin{abstract}
In today's society, manga has become an important Japanese cultural industry that has been exported to the whole globe. Because of this, its main social values have migrated to a group of consumers to whom, originally, it was not intended. In this information's transfer, highlights the presence of a series of titles, inscribed in science fiction, whose narrative presents a world of dystopian and apocalyptic character. This article attempt to investigate the meaning and themes present in those manga that delve into a theme of dystopian science fiction.
\end{abstract}

Keywords: manga, dystopia, science fiction, narrative, aesthetic.

\section{Cita bibliográfica}

Lorenzo Otero, J. L. «El manga de ciencia ficción: la distopía como reflejo de las inquietudes de la sociedad japonesa», en CuCo, Cuadernos de cómic, n. ${ }^{\circ} 10$ (2018), pp. 65-82. 


\section{Introducción}

En el siglo xx se ha producido una ampliación del campo cultural y artístico. Una transformación que ha aumentado el interés por las artes en la esfera pública y política. El consumo artístico y cultural ha crecido exponencialmente en la sociedad hasta convertirse en un importante ámbito en la vida diaria y en un significativo factor económico, con especial incidencia en los jóvenes. Unido a esto también ha crecido de forma evidente la práctica artística amateur y un aumento considerable en el ámbito del trabajo artístico. ${ }^{1}$

Uno de los principales agentes de esta ampliación cultural ha sido el cómic, con una especial incidencia, en la sociedad occidental, de su versión japonesa desde la década de 1980. El manga japonés presenta un tipo de cómic propio, que difiere totalmente del occidental, tanto en su forma como en su concepción estética o cultural. Un modelo donde los códigos emitidos son los propios de su sociedad. La difusión masiva del manga ha permitido que esta tradición comicográfica haya llegado a un público mayor que para el que está, previamente, destinado, transmitiendo así una serie de mensajes diferentes a los de la sociedad occidental.

Por ello, el objetivo del presente artículo es ahondar en la naturaleza de la ciencia ficción dentro de la historieta japonesa, para acceder a las realidades, inquietudes y recelos de una sociedad concreta como la nipona, por medio de la representación de sociedades futuras donde la distopía es protagonista.

\section{Metodología y estructura del artículo}

El artículo se estructura a través de una metodología que aplica herramientas de análisis histórico, artístico, sociológico, semiótico y técnico. Para ello, y tras una breve consideración sobre el manga, nos centraremos en: el concepto de la distopía y su relación con el género de la ciencia ficción; presentar y analizar los casos de estudio elegidos de mangas de ciencia ficción a través de cuatro títulos que plantean diferentes versiones de carácter distópico tanto en su vertiente narrativa como estética; para, finalmente, extraer unas conclusiones generales y críticas, cuyo fin es proponer posibles vías de apertura de la investigación.

${ }^{1}$ Rodríguez Morató, A. (ed.). La sociedad de la cultura. Barcelona, Ariel, 2007, pp. 11-12. 


\section{Consideraciones breves sobre el manga}

En primer lugar, hay que destacar que el término manga se refiere a todo cómic en el ámbito japonés. Pero su realidad es distinta a la del medio en cualquier otra localización, ya que es la representación cultural más reconocible del Japón actual. Su naturaleza popular se observa en todo tipo de elemento de la sociedad japonesa, desde el cine y la televisión hasta la publicidad o la educación, pasando por la moda o los videojuegos, por citar ejemplos significativos. El manga se convierte así en un elemento que forma parte de la vida diaria de los japoneses gracias a que su vertiente lúdica o pedagógica lo convierte en algo apto para cualquier público. ${ }^{2}$

El manga es un claro ejemplo de la sociedad extremadamente industrializada en la que se inscribe y un importante motor económico del país. Además de mostrar una cualidad propia de la cultura japonesa: la de asumir formas culturales de otras tradiciones y convertirlas en propias. En este caso, la asimilación de las formas de los principales autores del cómic estadounidense de principios del siglo xx y de la forma artística de autores de cartoon como Walt Disney son piezas fundamentales en el desarrollo de la estética del manga iniciado por Tezuka y que pervive hasta la actualidad. La forma de Japón de apoderarse de otras formas culturales y transformarlas en algo propio es algo conocido: desde la asimilación del arte o la escritura china, hasta el proceso de surgimiento del manga, se puede observar cómo Japón ha convertido en propias aquellas manifestaciones culturales que mejor se adecuan a su propia naturaleza cultural y/o artística. El manga se ha transformado en el medio cultural y artístico por antonomasia del Japón actual, una manifestación que es consumida por la mayoría de los sectores poblacionales, independientemente de edad, sexo o condición social.

\section{La distopía en la ciencia ficción}

Tradicionalmente, la acepción del término distopía suele relacionarse como un antónimo de la utopía, mostrando al igual que esta una sociedad hipotética totalmente diferente a la del contexto en que se inscribe y con una concepción evidentemente negativa. Si la propia idea de la utopía refleja una sociedad, gobierno o proyecto político ideal y claramente irrealizable, la distopía se construye sobre la premisa de la visión de un posible mundo peor que el real.

Pero no puede considerarse a la idea o concepto de la distopía como simplemente una versión contraria o distorsionada de la utopía. La relación entre ambas acepciones es más profunda de lo que tiende a considerarse. La diferencia entre ambos términos es únicamente axiológica, pero no material, basada en los juicios de apreciación del sujeto del discurso y no los contenidos del texto. Además, ambos conceptos tendrían como nexo a la ucronía, que sería el elemento que ayudaría a describir una historia paralela a la realidad y que mostraría un probable mundo futuro al lado del real. Como indica Luis Núñez Ladevéze: «Toda utopía, desde Moro a Orwell, es producto de la historia, responde a una mentalidad historicista

${ }_{2}$ Berndt, J. El fenómeno manga. Barcelona, Ediciones Martínez Roca, 1996, p. 9. 
y pretende detener la historia y escribir sus leyes en bronce, como corresponde a un ideal de perfección social.» ${ }^{3}$

En consecuencia, la distopía es la búsqueda de retratar lo que está mal en una sociedad concreta y mostrar los errores de la misma. Para ello, los autores utopistas — sean clásicos o contemporáneos- presentan una realidad soñada, que no se ha producido y que con total seguridad no es posible que se produzca. Se trata de una fábula que pretende mostrar los vicios de su sociedad y que intenta la supresión de estos. ¿Pero dónde sitúa esto la idea o concepto de la distopía? En la sociedad contemporánea, la distopía se ha convertido en lo que en su momento fue la utopía: un género literario donde se realiza una fábula sobre la sociedad en la que vive el autor.

Hoy en día, la distopía se ha convertido en el material imaginado, como anteriormente lo fue la utopía. Se ha convertido en la fábula, que utiliza la ciencia ficción como medio para mostrar los vicios y problemas de su contexto social, convirtiéndose en un elemento de crítica que expone su disentimiento, su protesta y su temor en los procesos que en dicha sociedad se producen. Al igual que ocurría con los fabulistas utópicos del Renacimiento, la ciencia ficción distópica se encuentra generalizada en la actualidad. La literatura, el cine, el cómic o los videojuegos de carácter distópico, por citar los ejemplos más reconocibles, presentan una visión pesimista de la sociedad futura, ya sea frente al proceso tecnológico, al industrializador, la masificación de la cultura, o el desequilibrio económico y de poder - siendo una reflexión constante de este último y el miedo a actitudes totalitarias una de las más características en el género- - La distopía se ha convertido en un subgénero ficticio cuyo fin es enseñar, reflexionar y, de paso, simbolizar los problemas de una sociedad traspasando los hechos que narra a un mundo lejano - y no tan lejano- con un fin claramente moralizador.

La distopía ha encontrado un espacio preeminente en la ciencia ficción, sobre todo en la literatura, el cine o el cómic. Son características básicas del citado género: un argumento en el futuro, el totalitarismo, la alienación del individuo, la disidencia de los protagonistas, la eliminación del pasado, la glorificación del estado totalitario y, sobre todo lo demás, una advertencia al lector sobre los vicios de la sociedad que da a luz al relato. ${ }^{4}$

En una sociedad global y con un mercado de la misma índole, en un momento concreto donde el cambio tecnológico es una constante permanente, donde el futuro es una experiencia diaria, los relatos distópicos buscan representar el cambio en sí por medio de la reestructuración del presente hacia la imagen del futuro a través de esa fábula utópica que hoy en día es la distopía, y que se ha extrapolado a los medios narrativos de la sociedad contemporánea: sea literatura, cine, cómic o, más recientemente, los videojuegos. ${ }^{5}$

3 Núñez Ladevéze, L. «De la utopía clásica a la distopía actual», en Revista de estudios políticos, n. 44 (1985) , p. 64.

${ }^{4}$ López Keller, M. E. «Distopía. Otro final de la utopía», en Reis: Revista española de investigaciones sociológicas, n. 55 (1991), pp. 7-23.

5 Jameson, F. Arqueologías del futuro. Madrid, Akal, 2009, pp. 335-351. 


\section{El manga de ciencia ficción: ¿̨retrato de los miedos de una sociedad?}

\section{El manga, la ciencia ficción y la sociedad japonesa}

Uno de los subgéneros más reconocidos del cómic japonés es el de la ciencia ficción. Los robots, los grandes avances tecnológicos, los impresionantes carteles de neón — todo ello situado en el espacio urbano- son algunos de los rasgos típicos asociados al manga de ciencia ficción - y a Japón en general, ya que lo que uno espera ver en dicho país es el futuro tecnológico hecho presente- - Es un entorno urbano donde las temáticas al más puro estilo cyberpunk $k^{6}$ están a la orden del día. La imagen que ofrece la ciencia ficción japonesa, a través del manga, es la visión de una ciudad futurista donde el hormigón, el cristal, la tecnología o la robótica lo dominan todo.

Pero ¿cuándo llega esa ciencia ficción al manga? Para responder a esta pregunta hay que volver al final de la Segunda Guerra Mundial y a la ocupación estadounidense del archipiélago japonés. ${ }^{7}$ Desde 1950 las fuerzas de ocupación se encargaron de censurar algunos temas tradicionales del manga - y la cultura japonesa en general- por temor a que pudieran incentivar el espíritu combativo del pueblo nipón y sus valores de obediencia y sacrificio basados en el bushido. Los jidai geki - temas de carácter histórico que muestran, sobre todo, el Japón feudal-, el judo, el kendo, el kárate y todos los deportes de combate japoneses fueron prohibidos. Como consecuencia de ello, el béisbol o la ciencia ficción pasaron a sustituirlos. ${ }^{8}$

En este clima es donde Osamu Tezuka crea uno de los más reconocidos personajes del manga de ciencia ficción: Astroboy (Tetsuwan Atom, 1952). Con esta obra, Tezuka establece dos máximas de la ciencia ficción japonesa: el progreso tecnológico y la fragilidad del espíritu humano. Atom - el protagonista de la historia - representa los beneficios de la energía atómica cuando la misma no se usa con una finalidad destructiva y la esperanza en los avances de la ciencia. Otra importante innovación que aparece es la superación de la temática infantil y el comienzo de un claro espíritu trágico en el manga de ciencia ficción. En este sentido, Tetsuwan Atom es una obra ejemplificadora de esta máxima, y lejos de apuntar a un desenlace satisfactorio, el autor es fiel al espíritu de la tragedia clásica: el pequeño héroe pasa por todo tipo de penalidades para sacrificarse finalmente, en una suerte de catarsis, redimiendo así al género humano de su cruel destino. ${ }^{9}$

Esta idea de lo trágico, de lo inevitable, es algo que se puede ver en la preocupación que el pueblo japonés tiene hacia las catástrofes naturales. Al situarse el archipiélago japonés en

${ }^{6}$ Subgénero de la ciencia ficción que se caracteriza por presentar visiones distópicas de la sociedad, con una tecnología avanzada y un nivel de vida empobrecido.

7 En este punto es importante incidir en que, si bien la ciencia ficción en el manga se populariza a partir de esta fecha, en la década de 1930 ya aparecen dentro del cómic japonés las primeras manifestaciones de dicho género en obras como Tanku Tanküro (Gajo Sakamoto, 1934).

${ }^{8}$ Koyama-Richard, B. Mil años de manga. Barcelona, Electa, 2008, p. 133.

9 Santiago, J. A. Manga. Del cuadro flotante a la viñeta japonesa. Pontevedra, Grupo dx5, 2010, p. 92. 
una de las zonas geográficas con mayor actividad sísmica del mundo, el pueblo nipón siempre ha temido a los terremotos y a las consecuencias de estos. Antiguamente, los japoneses invocaban al correspondiente dios protector y compraban una estampa para su reproducción. La leyenda decía que los seísmos eran provocados por un enorme pez gato que una divinidad aprisionada debajo de un peñasco, cerca del santuario sintoísta de Kashima. Este tipo de estampas — caracterizadas por el humor y la fantasía - eran muy apreciadas por el público. ${ }^{10}$ Desde estas páginas pensamos que la representación de este catastrofismo, por medio del citado ejemplo, puede ser un claro antecedente del uso del manga de ciencia ficción como metáfora del sentir de la sociedad japonesa.

Tal y como establece Gordon Mathews, es importante indicar que el orden social japonés se encuentra muy arraigado en la tradición y es, hasta cierto punto, extremadamente hermético. Se basaba en la idea del sacrificio y de respeto a las jerarquías. Un sacrificio cuya traducción sería: que el hombre debía sacrificarse por su profesión dedicándole todo el tiempo posible y siendo su absoluta prioridad, y la mujer debería realizar el mismo sacrificio y con igual intensidad, pero centrado en su familia. Al realizar ambos miembros de la pareja este esfuerzo, podrían vivir una vida plena y digna como adultos a la vista de la sociedad. Aquellas personas que no se supeditaban a dicho modelo eran considerados como parias y poseían muy pocas posibilidades de éxito profesional o personal. El orden social japonés del periodo 1960-1990, y en menor medida el actual, se basaba en la subordinación del individuo al grupo combinada con unos roles por sexo muy estrictos (los hombres vivían para el trabajo y las mujeres para la familia); se consideraba que las personas sólo podían vivir plenamente sus vidas adultas si aceptaban este sacrificio. Los valores tradicionales de la cultura japonesa todavía estaban vigentes en la organización social del siglo xx. Dicho orden se basaba en el ideal cultural de la armonía interpersonal y social (conocida como wa), que había que imponerse al individuo por medio de la perseverancia (gaman), cuyo fin era el de la subordinación y eliminación de la individualidad personal para poder adaptarse a los roles sociales adultos que habían sido previamente asignados. Aquellos que no lograban integrarse eran considerados egoístas y consentidos (wagamama), pensándose que no tenían sentido común (jooshiki) y, por ende, se les sometía a una enorme presión social (sekentei) para que su comportamiento fuera el deseado. ${ }^{11}$

Autores como Dominique Menkes establecen que existe una prolífica relación entre la cultura otaku y la posmodernidad, llegando a considerarla la primera cultura posmoderna gracias a la pérdida de referencias, al fin de los grandes relatos, la difuminación de la frontera entre autor y consumidor, entre el original y su copia. Además el individualismo de la sociedad contemporánea permite que exista una clara separación entre los mencionados tradicionales roles sociales japoneses, y cuyo ámbito de libertad puede ser el mundo del manga y el anime para la juventud — donde pueden evadirse de la presión social destinada al éxito escolar y el destino profesional determinado-.${ }^{12} \mathrm{Al}$ estar la sociedad japonesa do-

${ }_{10}$ Koyama-Richard, B. Op. cit., p. 43.

${ }_{11}$ Mathews, G. «La brecha generacional en Japón», en Anuario Asia-Pacífico, n. ${ }^{\circ} 1$ (2007), p. 489.

12 Menkes, D. «La cultura juvenil otaku: expresión de la posmodernidad», Revista Latinoamericana de Ciencias sociales, Niñez y Juventud, n. ${ }^{\circ}$ 10, 2012, p. 52. 
minada por estrictas y poco flexibles normas sociales, el manga podría considerarse como un medio donde la ideología oficial se contradice por medio de comportamientos y reacciones que jamás podrían permitirse en la vida real. ${ }^{13}$

La idea de un Japón posmoderno permite observar cómo en el citado manga de ciencia ficción pueden verse una mezcla de valores tradicionales típicamente japoneses - como la tradición guerrera y religiosa del país- con la tecnología de vanguardia y futurista. A través de la ciencia ficción los autores del manga reflexionan — de modo poco optimista - sobre su sociedad, los avances tecnológicos, la política o su propia historia enviándola al futuro e imaginándose cómo será el mismo.

En este contexto es muy interesante observar cómo la distopía se ha ido convirtiendo en un punto fundamental de este modo narrativo, y es algo que puede tener mucho que ver con su propia historia nacional. El proceso de apertura de Japón al mundo occidental a mediados del siglo XIX dio lugar a dos actividades claramente diferenciadas y contrarias: por un lado, se asumieron todo tipo de novedades - ya fueran artísticas, sociales, políticas o científicasde los países europeos; por otro lado, apareció un sentimiento de conciencia nacional que pretendía recuperar viejas tradiciones que pudieran reafirmar la identidad nipona frente a los modelos de Europa y América. Ese nacionalismo japonés, pronto derivó en un imperialismo y en la expansión militar japonesa por el continente asiático durante la primera mitad del siglo xx.

El siglo xx fue un periodo de profundos cambios en la política japonesa. El país desarrolló, en la primera mitad del siglo, un claro modelo imperialista y expansionista que acabó derivando en el conflicto bélico de la Segunda Guerra Mundial. En la segunda mitad del siglo, el país tuvo que hacer frente a la reconstrucción, a ser invadido por las tropas estadounidenses, a la expansión económica y a la renovación de sus instituciones. Esta renovación se cimentó en una creciente realidad social de carácter pacifista. Hasta hace poco tiempo, la política exterior japonesa se encontraba anclada en los principios subyacentes en el artículo 9 de la Constitución de 1947. Una realidad donde el país no necesitaba de un ejército profesional que lo salvaguardara o que pudiera entrar en conflictos bélicos a lo largo del globo. En la actualidad, y tras la reforma de la citada Constitución por el gabinete político de Shinzo Abe, el país busca crear un ejército que le permita poseer un papel más destacado en las estructuras de seguridad internacional, con especial incidencia en el continente asiático. Sus dirigentes aseguraban que su país debería ser respetado por la comunidad internacional con el fin de crear un marco de prosperidad en la región de Asia-Pacífico. Con este fin, se busca que Japón deje de ser solo una potencia económica de carácter global, para ser también una potencia diplomática y militar. Desde finales de la Segunda Guerra Mundial, Japón ha ido ampliando, poco a poco, sus efectivos militares, lo que ha quedado registrado en las diversas doctrinas y leyes desarrolladas por su parlamento. Uno de los puntos más importantes de este rearme del país es la polémica suscitada entre su propia población sobre el uso de armas

${ }_{13}$ Pablo Rodríguez, A. «La tragedia de la rosa y la espada. Elementos simbólicos de masculinización en la mujer fálica del Shônen Manga», Kokoro: Revista para la difusión de la cultura japonesa, n.o 14 (2014), p. 19. 
nucleares, aunque para la población debe continuarse con los tres principios no nucleares de la posguerra - no posesión, fabricación e introducción de materiales nucleares-. Es inevitable que cualquier país que consiga un cierto poder económico se convierta en una potencia militar, un hecho del que es muy consciente la población japonesa. ${ }^{14}{ }^{15} \mathrm{El}$ manga de ciencia ficción asimiló esas situaciones y las plasmó en viñetas que mostraron la visión de los autores sobre la sociedad a la que pertenecían.

La ciencia ficción cambia tras la Segunda Guerra Mundial. Se deja de plasmar un futuro utópico donde todo es nuevo y brillante, para mostrar un mundo oscuro y en el que las realidades sociales son totalmente desiguales. Desde estas páginas se propone la idea de que el pesimismo fruto de la tensión de la Guerra Fría, la paranoia y el temor a un conflicto nuclear provoca que las obras de ciencia ficción planteen un futuro distópico. Esta realidad, esta visión pesimista, se acrecienta en el manga, con una clara referencia a la propia historia del país nipón. El miedo a actitudes imperialistas, como la que dio lugar a la entrada de Japón en la Segunda Guerra Mundial, y a posibles inestabilidades de carácter político-militar, como los procesos que dieron lugar a los shogunatos ${ }^{16}$ históricos de Japón, son otra de las piedras sobre las que se sustenta el manga japonés. El intento constante, por parte de los villanos de manga, de intentar derrocar al gobierno establecido e instaurar un nuevo régimen político absolutista, sería una situación que conduciría al país de nuevo a actitudes totalitaristas, convirtiéndose en un recuerdo constante de los motivos que llevaron a la visión distópica y al afianzamiento de esta en el genero de la ciencia ficción.

La distopía presenta una reflexión crítica sobre los problemas de su tiempo a través de imágenes de lo que podría ser el futuro. El manga de ciencia ficción presenta a la distopía con rasgos muy característicos: una sociedad intensamente tecnologizada, donde existe una gran inestabilidad política e intensas luchas de poder entre los diversos grupos que aspiran a gobernar la nación - algo que recuerda a las luchas que dieron lugar a los respectivos shogunatos históricos de Japón-, la rebelión de la juventud contra esos cánones establecidos de la sociedad y/o un entorno devastado por las consecuencias de la guerra o de una catástrofe natural.

Existen una gran cantidad de mangas - y animes - que presentan algunas de estas constantes. La conocida Mazinger Z (Gô Nagai, 1972-1973) presenta una sociedad constantemente amenazada por el Dr. Hell — cuyo deseo es el de esclavizar a la humanidad - y cuya única posibilidad de salvación proviene del gigantesco robot Mazinger $Z$ - reflejo del avance tecnológico que sufría el país en la época-. Caso similar sería el de la serie anime Neon Genesis

${ }^{14}$ López I VIDAL, L. «La nueva estrategia de seguridad japonesa: la normalización de su diplomacia», en Anuario Asia-Pacífico, n. ${ }^{\circ} 1$ (2006), pp. 191-204.

15 También en esta línea, varias encuestas realizadas a la población japonesa indican que más del $80 \%$ de la misma sigue considerando que los tres principios sobre los que se sustenta la no proliferación de armas nucleares en su nación deben mantenerse. López i VidAL. Op. cit., pp. 196-197.

${ }_{16}$ Nombre japonés que se le da a diversos periodos de su historia en los que el país estuvo gobernado por el poder militar, tras la usurpación de funciones del emperador por parte de un shōgun, constituyéndose este último como el gobernante en funciones del archipiélago japonés, y estableciendo la figura del emperador en meramente representativa y carente de cualquier tipo de poder — ya fuera civil, militar, diplomático o judicial. 
Evangelion (Hideaki Anno, 1995-1996), ${ }^{17}$ que muestra un mundo futurista -y parcialmente destrozado- en el que un grupo de jóvenes, por medio de nuevo de robots gigantes, deben proteger a la humanidad contra seres monstruosos que atacan la Tierra. La representación de estas premisas se populariza desde la década de 1980, y dan lugar a una gran cantidad de series que siguen este modelo de sociedad futura distópica, como pueden ser: Ghost in the Shell de Masamune Shirow (1989-1990), The Legend of Mother Sarah de Katsuhiro Ōtomo y Takumi Nagayasu (1990-2004), o Blame! de Tsutomu Nihei (1998- 2003). ${ }^{18}$

Numerosos autores han relacionado las historias de carácter distópico con el impacto que en la sociedad japonesa tuvo el ataque nuclear contra las ciudades de Hiroshima y Nagasaki. El artista Takashi Murakami, dentro de su exposición Little Boy, insinúa que el manga se convertiría en un medio que permitiera expresar los traumas derivados de la hecatombe nuclear, en un medio que ayudaría a exorcizar los demonios de las bombas y los errores pasados. ${ }^{19}$ En este sentido, es muy interesante observar cómo, al igual que sucedía en $A s t r o b o y$, los finales de estas historias distópicas se enraízan con la voluntad de sus protagonistas de sacrificar su propia vida en pos de una era mejor.

\section{Fénix de Osamu Tezuka}

La conciencia de los errores cometidos en la guerra y el desenlace de esta, materializado en las dos bombas atómicas, son una constante en las obras que reflejan el futuro japonés. Como se ha indicado, uno de los primeros autores que se adentra en narrar el futuro es Osamu Tezuka por medio de Astroboy. Pero pocos años después de presentar al robot defensor de la humanidad, el mangaka plantea un no tan benévolo fin para el futuro por medio de su obra Fénix (Hi no Tori, 1954-1988).

Fénix es un conjunto de historias independientes que tienen como nexo común el tema del ave fénix. El ave que renace de sus cenizas permite al autor tratar el tema de los ciclos de creación y destrucción y, a partir de ello, dilucidar en torno a la relación entre lo humano y lo no humano, entre lo natural y lo artificial. La saga Fénix se puede calificar como un texto ecológico, por pivotar sobre una ética que rechaza el antropocentrismo y reconoce a la historia humana como simplemente parte de la historia natural. ${ }^{20}$

${ }^{17}$ La serie también tuvo una versión manga desarrollada a cabo por el autor Yoshiyuki Sadamoto y publicada por la revista Shönen Ace entre los años 1994 y 2013.

18 Aunque esto no solo se puede observar en la naturaleza del manga de ciencia ficción, otros géneros también han usado algunos de estos principios — con especial incidencia en la condición militarista y el temor a la creación de un estado totalitario-, como puede ser dentro del género del jidaimono, a través de personajes como Makoto Sishio de la serie Rurouni Kenshin (Nobuhiro Watsuki, 1994-1999) y su plan para derrocar al legítimo gobierno japonés de finales del siglo xıx, o el manga de fantasía con el Plan Ojo de Luna con el que el villano Madara Uchiha, de la serie Naruto (Masashi Kishimoto, 1999-2014), pretende esclavizar al mundo dentro de una ilusión perpetua.

19 Santiago, J. A. Op. cit., pp. 532-535.

${ }^{20}$ Marti Escayol, M.A. «La recepción de la obra de Osamu Tezuka en España», en Kokoro: Revista para la difusión de la cultura japonesa, n. ${ }^{\circ}$ extra 1 (2013), p. 5. 
En su segundo volumen, el autor japonés, traslada la acción a un hipotético futuro, en el año 3404, más concretamente, donde el ser humano habita en grandes ciudades — cinco en total en todo el globo- y su destino es regido por enormes supercomputadoras. El mundo natural ha sido destruido por la radiación y alterado por la conducta del ser humano. Tezuka, que usó la saga Fénix como una revisión crítica de ciertos periodos de la historia de su país, previsualiza el futuro como un mundo inhabitable y destinado a ser destruido. Los seres humanos se encuentran terriblemente alienados y supeditados bajo regímenes totalitarios —en este caso, el «líder supremo» sería una máquina - y los pocos que se rebelan son perseguidos y considerados parias.

El mundo, en las viñetas de Tezuka, está destinado a su aniquilación y el ser humano debe desaparecer para dejar paso al nuevo orden natural. Se plantea una visión cíclica y catártica de la historia, en el momento en el que el hombre destruya la tierra - y tras varios millones de años- la vida volverá al planeta - y el ser humano también-, con la esperanza de que esta vez no se cometan los mismos errores que en el pasado.

El estilo que desarrolla Tezuka en su obra se muestra marcadamente caricaturizado, con figuras que buscan ser lo más sintéticas posibles. Su narrativa es tendente a mostrar una interacción clara con el espectador, especialmente con la ruptura de la cuarta pared y el diálogo directo que el autor establece con el receptor de la obra en determinadas acciones y viñetas. Otra importante característica es la constante referencia a la cultura popular japonesa de su época, con lo que el autor hace importantes anacronismos en los diferentes periodos históricos y con lo que se intensifica la acción dibujada en ciertas viñetas. La visión que plantea en este volumen de Fénix es claramente devastadora: el mundo se esboza vacío, desdibujado, con una plasmación en unas viñetas donde predomina el blanco y los detalles son escasos en la naturaleza, y con lo que se deja constancia del estado en peligro de la sociedad que el autor está representando.

Fénix deja constancia de varias pautas claras que aparecerán en otros mangas similares: una crítica a la forma de toma de decisiones de la clase gobernante, un temor evidente al uso de las armas nucleares, la necesidad de rebelarse contra los que gobiernan y el tener que habitar el mundo natural con equilibrio y sin destruirlo. Tezuka, en pocas palabras, reflexiona sobre los grandes problemas de su tiempo y los plasma en viñetas con un marcado sentido de la tragedia: si la historia es algo cíclico, el desastre siempre aparecerá.

\section{Nausicaä de Hayao Miyazaki}

En la década de 1980, proliferaron los mangas cuya historia se centraba en un mundo postapocalíptico. Uno de los más reconocidos es Nausicaä, de Hayao Miyazaki (1982-1994) —que es, además, la principal obra larga que este importante cineasta japonés realizó en formato manga-. Su trama se sitúa en un mundo claramente postapocalíptico, donde hace miles de años se acabó con la civilización. La naturaleza se ha vuelto despiadada y venenosa para los seres humanos. La tecnología está prácticamente destruida, y la poca que existe no 
puede ser usada debido a la falta de conocimientos sobre ella. El mundo que presenta es preindustrial y prácticamente feudal.

En este caso, la distopía presentada es la de una humanidad que ha fracasado en el uso de la ciencia y la tecnología, condenando al mundo hasta el punto de que el propio entorno natural se ha vuelto contra el hombre. La guerra, las tensiones políticas y las luchas de poder entre imperios son constantes y recuerdan a las luchas políticas del feudalismo japonés. Ante este panorama, la princesa Nausicaä simboliza la humanidad, cuyo fin debería ser el de poder vivir en armonía y paz con su entorno.

El estilo que presenta la obra es claro y limpio. El autor establece un tipo de narración que se acerca a la estructura del storyboard ${ }^{21}$ en su aprovechamiento de la página y sus múltiples puntos de vista. Además, destaca la pulcritud del dibujo y su dominio de este. Las viñetas se encuentran plagadas de detalles y llenas de vida. Su representación de la naturaleza es marcadamente minuciosa, donde se puede observar una gran riqueza en la composición y la estructura. El estilo se acerca a una representación de carácter naturalista y realista.

La política, la religión y, sobre todo, la preocupación por el medio ambiente aparece en el relato mostrando la idea de lo perniciosa que puede ser la acción del hombre sobre su entorno, lo cual es la gran metáfora del manga. Como indica Alfons Moliné: «Fue precisamente un desastre ecológico en particular, la contaminación de la bahía Minamata, al sur de Japón, cuyos altos niveles de mercurio dañaron sensiblemente la pesca de la zona, lo que motivó a Miyazaki a elaborar su manga».22

La obra de Miyazaki hace hincapié en los vertidos químicos y el daño a la naturaleza, al mostrar una metáfora clara de que si no se protege el entorno natural también se está destruyendo el mundo humano, a la vez que se fija en la naturaleza belicosa del ser humano por medio de los dioses de la guerra y su enorme capacidad destructora.

\section{Akira de Katsubiro Ōtomo}

Pero si hay una obra de ciencia ficción que es sinónimo de distopía en el manga es, sin duda, Akira (1984-1990) de Katsuhiro Ōtomo. Con este trabajo, Ōtomo presenta a la ciudad de Tokio - en este caso Neo-Tokyo-, cuando la misma renace tras el cataclismo que significó la Tercera Guerra Mundial, convertida en una megalópolis donde la corrupción política es palpable y el descontento social evidente.

${ }^{21}$ También conocido como guion gráfico, es un conjunto de ilustraciones desarrolladas en formato secuencial con el objetivo de servir de guía de una narración. Suele usarse para previsualizar una animación o ver la estructura de un film antes de realizarse. Es el método de previsualización típico de la preproducción en la industria cinematográfica.

${ }^{22}$ Moliné, A. El gran libro de los manga. Barcelona, Glènat, 2002, pp. 178-181. 
Akira es la historia de la relación de amistad entre dos personajes: Tetsuo y Kaneda, cuyas vidas se ven envueltas en el entramado sociopolítico del Neo-Tokyo del futuro. De nuevo, aparece la trama con respecto al uso de las armas nucleares y, también de nuevo, se reflexiona sobre el peligro de estas. La premisa es sencilla: Akira, el ser que da nombre a la historia, posee unos enormes poderes psíquicos con los que puede desencadenar una destrucción de carácter nuclear. El mundo está devastado tras el conflicto de la Tercera Guerra Mundial, la civilización ha vuelto a resurgir de sus cenizas, pero el mundo natural se ha visto dañado y lo único que se observa son enormes ciudades de hormigón donde casi no hay árboles. La imagen de la desnaturalización de la tierra vuelve a estar presente.

También aparecen, de nuevo, las luchas por el control del poder. Los militares gobiernan y decretan en contra del parlamento para poder legitimarse en el poder. El parlamento se presenta como incapaz de mantener el orden social y lleno de burócratas corruptos. Se vuelve a observar el pasado histórico de Japón en esta idea: la incompetencia del emperador para mantener la estabilidad obliga a que un nuevo shögun militar se haga con el control del archipiélago. El shögun sería, en la narración, el poder de los militares, y el emperador se reflejaría en el gobierno elegido por los ciudadanos.

El miedo a la hecatombe nuclear se simboliza por medio del pequeño Akira. Los grupos políticos quieren usarlo para poder beneficiarse de él, para poder tener acceso tanto a sus posibilidades destructoras y a sus posibles beneficios. El debate sobre los posibles beneficios de la energía atómica está latente, aunque en este caso se muestra un claro miedo hacia la destrucción que la misma causó en el territorio japonés y que se plasma perfectamente en las primeras viñetas de la historia. Tampoco hay que obviar la desconfianza que genera que diversos grupos quieran poseer tal poder destructor, de forma que solo aquellos no alineados con el grupo que sea son representados como los que buscan el beneficio del niño y no su uso como arma de guerra.

En las páginas de Akira, Ōtomo presenta un dibujo claro y lleno de detalles, y muestra su dominio del blanco y negro. Su representación de la ciudad de Neo-Tokyo establece a la misma como un personaje más de la acción, no como un simple lugar. La calidad y cantidad de detalles hacen una constante referencia al lenguaje cinematográfico y a multitud de escenas de películas. Su virtuosismo con la mancha permite que se establezcan escenas donde la intensidad se observa en toda la viñeta. Una de las formas más destacables que presenta en la obra es el uso de la página como una totalidad, donde las viñetas muestran diversos puntos de vista que intensifican la acción que se narra en la misma, configurándola como la unidad fundamental de la obra. Destaca el uso que el autor realiza de las líneas cinéticas, con las que marca la intensidad de la acción, y que aumentan a medida que la narración se acerca a los momentos climáticos: es uno de los mejores ejemplos de su uso y aplicación en el manga.

Akira es una reflexión clara sobre la sociedad japonesa y su relación con los distintos factores sociopolíticos de la distopía nipona. Los protagonistas se rebelan contra el mundo establecido y contra la alienación con la que los gobiernos pretenden someter a la sociedad. La 
banda de moteros a la que pertenecen Tetsuo y Kaneda representa la lucha de los jóvenes japoneses frente al estricto sistema social nipón. La libertad de decidir por sí mismos es lo que se muestra por medio de sus acciones y actitudes. Además de incidir en el terror a que el orden social que existe en la sociedad posibilite actitudes que acerquen posturas militarizantes o imperialistas que se alejen de la paz social del país.

\section{Trigun de Yasubiro Nightow}

Trigun (1995-1997) — y su continuación Trigun Maximum (1998-2007)— de Yasuhiro Nightow representaría la visión de un futuro distópico apocalíptico. La premisa de la historia es sencilla y muy similar a las anteriores: En el futuro el planeta ha sido superpoblado y sus recursos naturales se encuentran, prácticamente, desaparecidos. Para asegurarse su supervivencia, los seres humanos envían al espacio a sus congéneres en animación suspendida, con el fin de que puedan sobrevivir en otros planetas.

Este argumento clásico de ciencia ficción pronto se convierte en un reflejo distópico cuando una de las naves se estrella con un planeta y todas las personas de esta deben volver a crear una civilización. El mundo fruto de ello es de lo más apocalíptico, donde los seres humanos luchan entre sí en un entorno desértico — que emula la estética del wéstern- y donde, prácticamente, no hay recursos.

Las células energéticas de las naves serán las que proveerán de vida los poblados, a modo de símil de las posibilidades positivas de la energía atómica, pero a su vez también reflejarán el poder destructivo de la misma. Dos seres «nacerán» de dichas células, dos entes con apariencia humana que poseerán el poder de usar esa energía para ayudar o destruir el mundo: Vash —el héroe de la historia — y Knives — su hermano y antítesis.

Con un estilo que podría denominarse expresionista, Trigun se presenta como una obra donde el conjunto representado en sus viñetas importa más que el detalle. El dibujo de $\mathrm{Ni}$ ghtow enfatiza un mundo desolado, de eterno desierto, donde todo es inhóspito y peligroso, muy influenciado por las imágenes más características del modelo fílmico del espagueti wéstern. Su forma representativa, tosca y desdibujada, ayuda a enfatizar la sensación de velocidad - tanto narrativa como representativa - sin recurrir al tradicional uso de líneas cinéticas y destacando más la sensación de la mancha sobre la línea remarcada por el característico uso del blanco y negro nipón.

Trigun se convierte en una metáfora de la propia historia contemporánea japonesa. Por una parte, el principal villano, Knives, simbolizaría a los señores feudales japoneses que pretenden gobernar al país por el poder de sus ejércitos - y representa, también, el militarismo japonés de la primera mitad del siglo xx-. Por otro lado, el héroe, Vash, sería la paz, fruto de la cual la civilización puede avanzar y prosperar. Además, ambos personajes son una actualización en forma de manga del concepto judeocristiano del bien y del mal —ambos son hermanos, ambos son denominados «ángeles» por parte de los seres humanos, y ambos 
están condenados a enfrentarse por la supremacía de sus ideales- cuyo fondo es un debate sobre el uso de la energía nuclear por parte del pueblo japonés.

De esta manera se establece un diálogo que pretende remarcar lo pernicioso que es el uso de dichas energías nucleares en la guerra y contra la población civil, pero también se muestra que la misma puede ser muy beneficiosa para la humanidad usándose con criterio. E1 enfrentamiento entre ambas ideas, entre ambas entidades, no da lugar a una respuesta satisfactoria, ya que debe ser el propio ser humano el que decida sobre ello y sea consciente de sus acciones. Además, la figura del héroe se relaciona con la imagen de la tragedia, debido a su predisposición de dar su vida a cambio de conseguir vencer a su enemigo y conseguir un periodo de paz.

\section{Conclusiones}

Con esta investigación se ha intentado observar si se constata una evidente relación entre el tono distópico del manga y los miedos de la sociedad a la que pertenece dicho medio. Es evidente que la preocupación sobre la energía atómica, el totalitarismo o la relación del ser humano con la naturaleza son constantes que han aparecido en las obras analizadas. Además, en una sociedad con una estructura tan hermética como la japonesa, el manga se ha convertido en el medio por antonomasia donde mostrar las inquietudes y preocupaciones de sus ciudadanos - sean de la edad que sean-. El reflejo de un planeta devastado se puede ver en cualquiera de las obras citadas, al igual que la constante de las luchas de poder entre grupos ideológicamente diferenciados - y que, como se ha indicado, recuerda mucho a la propia historia de Japón-. Sin duda, el miedo a una nueva catástrofe sea natural, sea causada por el hombre, se refleja con asiduidad en las distopías del manga, donde posee una enorme preponderancia el miedo a que las armas nucleares puedan volver a ser usadas contra la población civil. Otra sensación permanentemente representada es la constante preocupación que la sociedad japonesa tiene sobre el carácter beligerante de su propia sociedad. Es evidente que las actitudes beligerantes de las clases gobernantes y políticas de Japón han influenciado a toda una generación de autores de manga claramente identificados con los valores pacifistas de su Constitución. Al ser el manga un medio al alcance de todos los públicos y todas las edades, los mangakas lo han usado con un carácter claramente antibelicista $y$ en el que han presentado lo pernicioso que es que actitudes imperialistas existan en una sociedad que, desde la ocupación estadounidense, se ha asentado en una democracia pacifista y sin un ejército propio. No sorprende, de esta manera, que la lectura en profundidad de multitud de obras japonesas muestre una constante de lucha entre una sociedad que lucha por su libertad y su vida en paz — representada por los respectivos héroes de los mangascontra un aspirante a tirano que pretende devolver al país a un modelo de shogunato o una sociedad de carácter totalitario. En el manga distópico de ciencia ficción es evidente esta premisa, la cual se ve aderezada por el temor de que el uso de las armas nucleares vuelva a atentar contra la población civil, lo que convierte a la misma en la gran damnificada de los errores cometidos por las decisiones de una élite gobernante que, realmente, no sufrirá los efectos reales de una catástrofe de dicha índole. En este punto sería interesante observar las 
diferentes vías del manga y sus diferentes géneros o temáticas para observar si ese temor a actitudes pasadas, totalitarias y belicosas también son una constante clara en su narración y representación, al igual que parece estar constatado en el propio género de la ciencia ficción. Por último, queremos destacar la importancia de la figura del héroe -o héroes- en estas obras, cuya ideología le permite luchar por una estructura social que no se encuentre amenazada por actitudes beligerantes, que intenten menoscabar la libertad del pueblo japonés de vivir en paz. Una imagen que se puede reflejar en la posibilidad de la muerte de los protagonistas con la única finalidad que la de permitir que sea la propia población la que dirija sus destinos. 


\section{Bibliografía}

BArbieri, D. Los lenguajes del cómic. Barcelona, Paidós, 1993.

Berndt, J. El fenómeno manga. Barcelona, Ediciones Martínez Roca, 1996.

Cantero Pastor, J. L. El cómic: plástica y estética de un arte figurativo y cotidiano. Madrid, Universidad Complutense de Madrid, 1993.

García, S. La novela gráfica. Bilbao, Astiberri, 2010.

Gil, F. y Segado, F. (eds.). Teoría e historia de la imagen. Madrid, Editorial Síntesis, 2011.

Gravett, P. (ed). Manga. La era del nuevo cómic. Madrid, H.Kliczkowski, 2004.

Koyama-Richard, B. Mil años de manga. Barcelona, Electa, 2008.

Jameson, F. Arqueologías del futuro. Madrid, Akal, 2009.

López Keller, M. E. «Distopía. Otro final de la utopía», en Reis: Revista española de investigaciones sociológicas, n. ${ }^{\circ} 55$ (1991), pp. 7-23.

López I VIDAL, L. «La nueva estrategia de seguridad japonesa: la normalización de su diplomacia», en Anuario Asia-Pacífico, n. ${ }^{\circ} 1$ (2006), pp. 191-204.

Mathews, G. «La brecha generacional en Japón», en Anuario Asia-Pacifico, n. ${ }^{\circ} 1$ (2007), pp. 485-492.

Marti Escayol, M. A. «La recepción de la obra de Osamu Tezuka en España», en Kokoro: Revista para la difusión de la cultura japonesa, n. ${ }^{\circ}$ extra 1 (2013).

Menkes, D. «La cultura juvenil otaku: expresión de la posmodernidad», en Revista Latinoamericana de Ciencias sociales, Niñez y Juventud, n. ${ }^{\circ} 10$ (2012), pp. 51-62.

Moliné, A. El gran libro de los manga. Barcelona, Glènat, 2002.

Muro Munilla, M. Á. Análisis e interpretación del cómic. Ensayo de metodología semiótica. Logroño, Universidad de La Rioja, 2004.

NúÑez Ladevéze, L. «De la utopía clásica a la distopía actual», en Revista de estudios políticos, n. 44 (1985), pp. 47-80.

— «Sobre el proceso de la utopía a la distopía». Revista de estudios políticos. № 52 (1986), pp. 111-124. 
Pablo Rodríguez, A. «La tragedia de la rosa y la espada. Elementos simbólicos de masculinización en la mujer fálica del Shônen Manga», en Kokoro: Revista para la difusión de la cultura japonesa, n. ${ }^{\circ} 14$ (2014), pp. 14-22.

Rodríguez Morató, A. (ed.). La sociedad de la cultura. Barcelona, Ariel, 2007.

Santiago, J. A. Manga. Del cuadro flotante a la viñeta japonesa. Pontevedra, Grupo dx5, 2010. 